\title{
Hegel: el idealismo absoluto como slum naturalism
}

Julián Ferreyra

\section{(2) OpenEdition \\ Journals}

Edición electrónica

URL: http://journals.openedition.org/ref/622

ISSN: 2258-014X

Editor

EuroPhilosophie Editions

Referencia electrónica

Julián Ferreyra, « Hegel: el idealismo absoluto como slum naturalism », Revista de Estud(i)os sobre Fichte [En línea], 10 | 2015, Publicado el 01 septiembre 2015, consultado el 08 septiembre 2020. URL http://journals.openedition.org/ref/622

Este documento fue generado automáticamente el 8 septiembre 2020.

(c) EuroPhilosophie 


\title{
Hegel: el idealismo absoluto como slum naturalism
}

\author{
Julián Ferreyra
}

"[En el slum naturalism] la idea no teme las villas
miserias [slums], no tiene miedo de ninguna de las
suciedades de la vida"
Mikhail Bakhtin

1 " $\mathrm{j}$ Al aniquilar el mundo verdadero hemos aniquilado el aparente!", aseveró Nietzsche en su "historia de un error" señalado que ese destino común del mundo inteligible y el sensible en la aniquilación era inherente a la teoría de las Ideas de Platón (allí donde según Nietzsche el error había comenzado): "Y quien no sepa esto, ignora lo fundamental". Así, la historia del error no es, desde la perspectiva hegeliana, más que la historia del malentendido de las Ideas platónicas. No narra la historia del idealismo, sino del falso idealismo (Schlechten Idealismus). En cambio. el idealismo bien entendido, debe ser absoluto, o no será. Si no es absoluto, es falso ${ }^{3}$. Como una moneda de oro falsa ante la prueba del mordiscón o el ácido nítrico, el idealismo que no resista la prueba del absoluto no puede sostenerse; entra en una espiral regresiva que termina por aniquilar sus propios fundamentos. Palidece, se vuelve inasequible, desconocido, inútil, superfluo, refutado en sí mismo. El Grund deviene Ungrund. Caemos en un abismo de una profundidad sin fondo.

Mostraremos en estas páginas que no se trata de una perspectiva nietzschana o posmoderna, sino que es característica del idealismo alemán bien entendido. Se trata de evitar lo que Fichte llama idealismo trascendente o "a medias" y Hegel Schlechten Idealismus. Si la Idea trasciende a lo existente, finito, sensible, natural, mortal, limitado, eso a lo cual trasciende le escapa. Si algo escapa a la acción de la Idea, todo escapa: por ese punto de fuga la Idea, y todas las aspiraciones de la filosofía, se pierden. Tiene que haber inmanencia. La Idea debe estar en todas las cosas, y todas las cosas en la Idea. 
Incluso el barro, incluso los pelos, incluso la basura, incluso los monstruos, las aberraciones, las máculas y fallas (aunque también lo justo, lo bello y lo bueno - y también el hombre, el fuego y el agua, el amor y el Estado). La Idea no debe temer el más crudo slum naturalism - porque sólo en tanto alcanza la más sucia cloaca es capaz de ser bella y verdadera. Particular en lo más universal, singular en lo más universal, magnífica en lo despreciable: sólo así la filosofía clásica alemana puede aspirar a resolver el antiguo problema de la participación. Se trate de Fichte, de Schelling o Hegel, en eso consiste el idealismo: idealismo absoluto 4 . Y. cuanto más se sumerge Hegel en el estudio de su doctrina y de sus textos durante sus Lecciones, ya se encontraba en lo fundamental en Platón:

Esta determinabilidad consiste en que lo uno sea en lo otro, en lo múltiple, en lo distinto, idéntico consigo mismo. Es esto lo que constituye lo único verdadero y lo único interesante para el conocimiento en lo que se llama filosofía platónica; y quien no sepa esto, ignora lo fundamental ${ }^{5}$.

\section{La doble pinza empírico-idealista}

3 Nietzsche creyó que el paulatino palidecer hasta la disolución era inherente a la perspectiva filosófica idealista. Su historia del error comienza en Platón y termina en Zarathustra, se inicia con la afirmación del "mundo verdadero" como "la forma más antigua de la Idea" y culmina en el "final del error más largo", donde la aniquilación del mundo verdadero implica la del mundo de las apariencias. La historia del error, tal como la narra Nietzsche, tiene algo de fatal. Una vez que empezamos por el "mundo verdadero" opuesto al mundo aparente, la cuestión está jugada, y juzgada. Hegel es plenamente consciente de ello. Por eso, cuando elige la noción de "Idea" para su Ciencia de la lógica -y para ocupar el último estadio de la misma, su punto cúlmine-, piensa sin duda que este concepto lejos de contribuir a ese dualismo fatal, es el único que pude disolverlo (en deuda con los distintos desarrollos sobre este punto que Fichte había realizado). El concepto de Idea no es unilateral, no implica una oposición al mundo aparente, sino que es el único que, bien entendido, puede salvar a la filosofía de su aparente condena a bailar perpetuos tangos fatales con su propia aniquilación. Pero esta buena comprensión de la Idea, para investir toda la dignidad y potencia que exige ocupar la cúspide del movimiento lógico, debe poder aplicarse ya desde Platón. Debe haber una historia del acierto que "deconstruya" la historia del error que la mala comprensión del idealismo ha construido - y que en tiempos de Hegel parece estar ganando la pulseada merced a las malas artes de la Popularphilosophie. Tiene que haber un idealismo bien entendido ya en Platón, ya comprobable en la interpretación de las Ideas platónicas. Este esfuerzo de Hegel por construir la auténtica historia de la Idea a partir de la cual valorizar su propio idealismo se observa claramente en las Lecciones sobre la historia de la filosofía:

De acuerdo con Platón lo absoluto ha de buscarse en el pensamiento y toda realidad es pensamiento: no el pensamiento unilateral o el pensamiento concebido en el sentido del idealismo malo [schlechten Idealismus], según el cual el pensamiento reaparece en uno de los lados, se concibe como pensamiento consciente y se enfrenta a la realidad, sino el pensamiento que abarca en una unidad tanto la realidad como el pensar, el concepto y su realidad en el movimiento de la ciencia, y la idea de un todo científico ${ }^{6}$.

El blanco de la crítica nietzschena es el schlechten Idealismus, un pensamiento unilateral que se enfrenta a un realidad que no es más que apariencia. Pero esta crítica no afecta a 
Platón sino a una mala interpretación de su doctrina, ya que "mediante la exposición de sus ideas, Platón puso al descubierto el mundo intelectual, pero sin ver en él un mundo situado más allá de la realidad, en el cielo, en un lugar distinto, sino el mundo real"7. En el idealismo no se trata, como afirma Sandkühler en sus obras recientes, de "afirmar la existencia de entidades espirituales (Ideas), que no se pueden reducir (nicht reduzierbar) a entidades materiales". Eso es idealismo malo que, en tanto radicalmente infundado, se opone al idealismo hegeliano, absoluto, absolutamente fundado en algo que, coherentemente, no puede ser ningún idealismo parcial. Si la schlechten Unendlichkeit entra en la espiral ascendente hacia la nada de la progresión infinita ${ }^{9}$, el schlechten Idealismus entra en una regresión infinita que socava sus propios fundamentos hasta su disolución.

Por una parte, entonces, la historia del error de Nietzsche no es la historia del idealismo sino del falso idealismo, de las malas interpretaciones, superficiales y esquemáticas, que traicionan la indagación filosófica que lo caracteriza. Por otra parte, esa historia tiene una contra-trama necesaria, que Nietzsche supone pero no enfatiza: la del realismo que "considera al pensamiento como algo formal, y tiene sólo a lo sensible por la realidad" ${ }^{10}$. Sólo en tanto se incrementa la creencia dogmática en lo sensible, la Idea se va desvaneciendo. Se piensa que lo sensible, lo empírico es lo verdadero y por ese motivo, se concibe al pensamiento sólo como formal, irreal y vaporoso. Desde la perspectiva empirista, señala Hegel en sus Lecciones sobre la historia de la filosofía, es imposible comprender la filosofía platónica, y el idealismo todo. Por ello, el empirismo está absolutamente implicado en la historia nietzscheana del error, ya que ese empirismo implica la afirmación de un mundo verdadero: el sensible. La reducción de lo ideal a apariencia es sólo su contrapartida necesaria.

El falso idealismo y el falso realismo, al afirmar la "verdad" de un lado, relegan al otro a la "apariencia". Tal es el error, cuyo final anuncia Zaratustra, y cuya disolución es el gran esfuerzo del idealismo, que Hegel remonta hasta Platón. El programa del idealismo absoluto es entonces acabar la oscilación entre la afirmación de la experiencia y la defensa del pensamiento abstracto:

Ambas direcciones [realismo e idealismo] vienen a converger en un punto común, ya que también la experiencia, por su parte, se esfuerza por derivar de las observaciones, principios y leyes generales; y a su vez el pensamiento, partiendo de lo general abstracto, necesita darse un contenido determinado, por donde lo apriorístico y lo aposteriorístico no forman dos campos absolutamente deslindados. En Francia, logró imponerse más bien lo general abstracto; en Inglaterra prevaleció, por el contrario, en general, el criterio de la experiencia, que todavía hoy goza de gran predicamento en aquel país; Alemania, en cambio, tomó como punto de partida la idea concreta, el interior del hombre, pleno de ánimo y espíritu ${ }^{11}$.

7 La perspectiva del absoluto comienza cuando se comprende que el error reside en la contraposición de dos perspectivas. No hay ni un mundo verdadero (sea el de las Ideas en sí o el de las cosas en sí), ni un mundo aparente (sea el de las bloße Ideen o las bloße Sache). No se puede reducir es la filosofía a un juez que debe tomar partido por una de dos partes ya supuestas como en disputa. La "convergencia" entre idealismo y realismo no quiere decir que esta oposición funde la Idea concreta, que la génesis de Idea concreta se deba rastrear en la lucha de estos contrarios. Por el contrario, el punto de convergencia es que se basan en un único malentendido, un mismo error. La historia de la filosofía de Hegel no debe comprenderse como opuestos que hacen posible su propia superación, sino como una radical crítica a tales oposiciones. Tal es el error de hacer de 
las determinaciones de la reflexión y la Doctrina de la esencia la clave de bóveda del sistema hegeliano: nunca nos libraremos de los opuestos, que estarán en el fundamento. Nunca nos libraremos de la potencia destructiva de la contradicción, si no comprendemos que es efecto apariencial de la lógica profunda del concepto, que da cuenta de las contradicciones sin suponerlas, sino produciéndolas. La filosofía de Hegel no es una filosofía de la contradicción, las contradicciones no son el motor de la historia. La Idea concreta explica lo real (no es el alma bella, comprende las sangrientas luchas que configuran la historia universal), pero no por ello calca sus determinaciones de las oposiciones empíricas.

8 El idealismo absoluto aniquila simultáneamente la Idea "verdadera" y el mundo aparente de la existencia. Los opuestos no sostienen la dialéctica: sólo la disolución de la lógica esencialista de la oposición permite alcanzar el punto de vista del concepto. La "idealidad de lo finito" implica la aniquilación de lo finito en tanto apariencia y de lo infinito en tanto mundo verdadero, pálido, inasequible, superfluo.

\section{La cárcel de la mente de Dios}

9 Existe una tensión, una oscilación, una tendencia, casi un esfuerzo del entendimiento humano de lanzarnos hacia los extremos. La filosofía camina por el estrecho, infinitamente estrecho desfiladero que pende entre ellos. El resultado del schlechten Idealismus es la nada ${ }^{12}$, y la inclinación de todo idealismo es traicionarse cayendo hacia esa nada. Todo idealismo puede caer en en el idealismo malo, como toda infinitud en la mala infinitud. De Platón a Hegel, los idealistas están perpetuamente trastabillando, perpetuamente a punto de caer en el abismo del idealismo malo.

La caída nos lleva al dogmatismo de la idea en sí, frente al cual las cosas serían meras cosas, bloße Sache. Tal es la interpretación de sentido común del idealismo, y que se le atribuye livianamente a Platón: el ámbito sensible está poblado de meras cosas, apariencias, sombras, fantasmas. Lo único real es el ámbito inteligible, las Ideas, el "mundo verdadero". Lo existente sólo existe en la medida en que copia las Ideas, o participa de ellas. Una de las pocas referencias al platonismo en la Ciencia de la lógica coloca a Hegel en tal perspectiva interpretativa del legado de Platón:

Las Ideas platónicas se encuentran en el pensamiento de Dios, como si fueran cosas existentes, pero situadas en otro mundo o región, fuera de los cuales se encontraría el mundo de la realidad [Welt der Wirklichkeit] el cual tendría una sustancialidad diferente a la de aquellas ideas, y que sólo por esta diferencia sería real [reale ${ }^{13}$.

11 El malentendido consiste en creer que la verdad de las Ideas está protegida en un ámbito trascendente: eminentemente, en la mente de Dios. Las ideas transformadas "si no precisamente en cosas, por lo menos en una especie de esencias trascendentes fuera de nosotros"14, son la contrapartida de un mundo sensible que se toma en realidad como lo único que tiene realidad y "que Platón reputa como simples sombras"15. Proteger las Ideas en la mente de Dios o en el mundo verdadero es la contrapartida del desprecio del mundo sensible. Pero, como afirma Hegel cuando en las Lecciones se sumerge en la interpretación de Platón (a diferencia de la mención al pasar que realiza en la Ciencia de la lógica, donde se deja atrapar por el platonismo del sentido común), "no es eso lo que Platón quiere decir, ni es tampoco la verdad"16. Esa es la fuente de los malentendidos o tergiversaciones que impiden, según Hegel, comprender la filosofía platónica ${ }^{17}$. 

la Ciencia de la lógica de acuerdo a la cual la Idea es "la representación de Dios, tal como está en su ser eterno, antes de la creación de la naturaleza y de un espíritu finito"18. Pensar la Idea escindida de la Naturaleza o el espíritu finito no es pensar la idea, sino tergiversarla. La Idea no existe "antes", en la plenitud de sus determinaciones lógica, y luego se despliega. La Idea es siempre ya naturaleza, siempre ya espíritu finito. Están imbricados, como lo muestra el silogismo de silogismos con el que cierra la Enciclopedia de las ciencias filosóficas: lógica-naturaleza-espíritu, pero también naturaleza-espírtulógica y espíritu-lógica-naturaleza ${ }^{19}$. Cuando en la Ciencia de la lógica dice "antes de la creación de la naturaleza y un espíritu finito", se refiere sólo al "primer fenómeno", al primer silogismo. Pero la Idea está también "después", como conclusión (en el segundo) y, fundamentalmente, como medio, "que se escinde en espíritu y naturaleza" ${ }^{20}$, en el tercero. Por ello no pude ser adecuada la distinción entre el pensamiento de Hegel y el de Fichte que ensaya Goddard:

Para Hegel, la encarnación es inteligible solamente a partir de la Lógica de la Idea eterna, como la realización en el mundo humano de la conversión reconciliadora implicada con necesidad absoluta en la vida divina [...] En cambio, para Fichte, la encarnación pone inmediatamente lo Eterno en el interior del tiempo, lo implanta en él, de manera que no se puede pensar ningún desarrollo de lo Eterno por fuera del que aparece y adviene en la temporalidad ilimitada de una historia humana. ${ }^{21}$

Según este esquema, en Hegel la Idea eterna tiene un desarrollo autónomo y luego se encarna en el mundo humano con una necesidad absoluta que está implicada en la vida divina, independientemente del mundo humano y natural. Primero la eternidad, luego el tiempo. Esta interpretación implica una separación, un enfrentamiento de dos planos (ámbitos) que Cristo logra reconciliar (y la reconciliación misma está implicada con la necesidad absoluta en la vida eterna). La eternidad implica realización. Pero esto falsea el esquema del idealismo absoluto y supone una oposición (primero idealismo, luego materialismo, hasta la convergencia según avatares temporales regidos por la necesidad ideal) que, como vimos, es un punto de vista insuficiente. Lo que Goddard atribuye a Fichte es en cambio mucho más ajustado a lo que interpretamos en Hegel: no se puede pensar ningún desarrollo de la Idea por fuera de lo que aparece y adviene el al temporalidad. Lo eterno está inmediatamente en el interior del tiempo, como su pulso viviente y todo su desarrollo es el de la historia humana ${ }^{22}$. No hay resto. No hay una reserva de divinidad. No hay un Yo absoluto antes del Yo limitado, diría Fichte; no hay una Idea antes de la naturaleza y el espíritu, diría, bien entendido, Hegel.

Nietzsche considera que el primer paso de la "historia de un error" es la separación del mundo verdadero (la Idea, el elemento lógico) y el sensible (eso sí, "alcanzable" para el sabio, el piadoso, el virtuoso). Pero Hegel impugna esa lectura escindente como tergiversación incluso en Platón: las ideas no son un "mundo verdadero" sino que son por derecho el mundo real. Las ideas son el mundo de la realidad, y no se enfrentan a él. Que esté en la naturaleza de las Ideas realizarse, no quiere decir que aspiren a realizarse (ni siquiera en la mente de Dios antes de la creación). No son ni fueron quimeras. Por el contrario, son reales, y por lo tanto no existen independientemente de su desarrollo en el mundo:

Cuando un ideal encierra de suyo verdad por medio del concepto, no puede ser una quimera precisamente por ser verdadero, pues la verdad no es nunca una quimera (...) El verdadero ideal no aspira a realizarse, sino que es real, y además lo único real $^{23}$. 


\section{Dignificar lo empírico}

15 Si la Idea es verdadera en tanto realizada, el enfrentamiento, la diferencia de sustancialidad, son lo falso. Idea y realidad tiene la misma sustancialidad, no se enfrentan ${ }^{24}$. La lógica del enfrentamiento le baja simultáneamente el precio a la idea y a la realidad (haciendo de las ideas meras abstracciones y de las cosas meras sombras). El idealismo absoluto, en cambio (lo que Platón quiere decir, y también la verdad) debe subirle el precio a ambos En efecto, la verdadera dignidad de la Idea no es la quimérica fantasía de una perfección impoluta:

Quien tenga presente aquel ideal falso [un ideal de hombre perfecto que no se encuentra en la masa de ningún pueblo, corriente en el mundo cristiano], equivocado, encontrará siempre al hombre lleno de faltas y de máculas [Schwäche und Verderbnis] y no tendrá por realizado aquel ideaa ${ }^{25}$.

La falta del mundo corresponde a una abstracción de lo ideal. Pero la Idea concreta se realiza, es verdadera en las supuestas faltas y máculas. Y al mismo tiempo, el mundo de la realidad es la realización de la idea, y en esto consiste su dignidad, su verdad. Pero este mundo de la realidad (finito, sensible, limitado, terrestre) es verdadero, en tanto es él mismo verdadero, no como sombra, copia o apariencia. No puede permanecer como aparente, no puede ser mera sombra. Pero tampoco puede ser "a la inglesa", un materialismo que parta de la experiencia, la mera experiencia, para derivar "observaciones, principios y leyes generales" ${ }^{26}$. El resultado del gesto empirista de partir de una experiencia sin Idea que se realiza científicamente en aquellas leyes, es tener como resultado meras abstracciones y generalidades, pero no Ideas ${ }^{27}$. Así como partir de Ideas aisladas en la mente de un Dios trascendente tenía como contrapartida una realidad sombría y falsa (y, siguiendo la historia de un error, terminaba por aniquilar la propia Idea, marchita en su cárcel divina), partir de una experiencia aislada en un mundo trascendente de cosas en sí tiene como contrapartida un pensamiento abstracto y pálido (que terminará por el desprecio de los conocimientos muertos de la ciencia, el luddismo y la superstición).

17 ¡Al eliminar el mundo verdadero hemos eliminado también el aparente! Esto implica tanto eliminar el mundo verdadero ideal (ámbito trascendente, separado, eminente, encerrado en la mente de Dios), como el mundo verdadero material (mundo de cosas que existen en sí independientemente del pensamiento). De la misma manera, al dignificar la Idea en su realización, hemos dignificado el mundo real en su idealización. Por lo tanto, la idealidad de lo real no implica su aniquilación, ni su conjura, ni su puesta entre paréntesis, sino su emergencia del ámbito sombrío al cual la tergiversación de las Ideas platónicas lo había condenado. Estas son las consecuencias lógicas, estrictamente lógicas, del discurso hegeliano. En este proyecto, no sólo el "espíritu humano finito" o "la temporalidad ilimitada de una historia humana" tienen un rol eminente, sino también la filosofía de la naturaleza (respetando todos los miembros del silogismo de silogismos): "En Platón empezó la filosofía a esforzarse más y más por llegar a conocer lo más determinado (...) La filosofía platónica de la naturaleza nos enseña, por tanto, a conocer más de cerca esta esencia del universo" ${ }^{28}$. Pero, ¿estamos listos para extraer todas las consecuencias de este conocimiento de la esencia del universo? ¿Estamos listos para la Idea de que lo humano, demasiado humano, y lo natural, demasiado natural son, en su idealidad, no algo que tiene que ser superado, sino algo que debe ser 
abrazado? ¿Estamos listos para abrazar el pelo, el barro, la basura, las faltas y las máculas?

\section{El temible abismo de pelos, barro y basura}

Platón no es capaz para Hegel de realizar su propio proyecto. Platón aspira a una filosofía de la naturaleza que se acerque a la esencia del universo, pero "sin embargo, no podemos detenernos aquí en lo especial [Spezielle], que, por lo demás, no ofrece tampoco gran interés" 29 . En lo "especial", la filosofía platónica de la naturaleza fracasa. Estas dificultades del proyecto para llevarse a cabo provienen, por una parte, de las limitaciones del conocimiento natural de su época. Ese conocimiento "no alcanza" suficientemente de cerca la esencia positiva del universo y, por otra parte, la filosofía basada en él quedará "desactualizada" en la media en que la ciencia avance. Pero el argumento por el atraso científico es pobre y positivista en extremo. Se aplica a Platón, a Hegel, al estructuralismo, a Deleuze. Se aplica, de hecho, en potencia, a cualquier filosofía contemporánea, por muy actualizada "científicamente" que esté. Siguiendo el curso de las revoluciones científicas, su "progreso" y sus cambios de paradigma, en el futuro toda filosofía que haga pie en la ciencia quedará desactualizada - y, por otra parte, nunca el conocimiento positivo alcanzará acabadamente la esencia del universo. En el límite, el argumento positivista aspira a impugnar todo uso filosófico de la ciencia. Pero el enfoque positivista no es lo interesante de la filosofía de la naturaleza, de Platón a Hegel. Después de todo, es la historia del error materialista: por ese camino, cada vez quedará más alienada de la idea concreta y su conocimiento se alejará, en vez de aproximarse, a la esencia del universo. Lo interesante de la relación de Platón con la filosofía de la naturaleza es el límite intrínseco.

Platón no avanza en el conocimiento sensible porque los conocimiento científicos de su época no alcanzan, pero también por el temor a perderse en esas necedades "sin fondo". Así lo muestra un pasaje bastante célebre del Parménides de Platón:

Parménides- $Y$ en lo que concierne a estas cosas que podrían parecer ridículas, tales como pelo, barro y basura, y cualquier otra de lo más despreciable y sin ninguna importancia, ¿también dudas si debe admitirse, de cada una de ellas, una Forma separada y que sea diferente de esas cosas que están ahí, al alcance de la mano? ¿O no?

- ¡De ningún modo!, repuso Sócrates. Estas cosas que vemos sin duda también son. Pero figurarse que hay de ellas una Forma sería en extremo absurdo. Ya alguna vez me atormentó la cuestión de decidir si lo que se da en un caso debe darse también en todos los casos. Pero luego, al detenerme en este punto, lo abandoné rápidamente, por temor a perderme, cayendo en una necedad sin fondo. Así pues, he vuelto a esas cosas de las que estábamos diciendo que poseen Formas, y es a ellas a las que consagro habitualmente mis esfuerzos"30.

La forma dialógica impide, por cierto, hacer afirmaciones muy taxativas. El temor expresado por el personaje del joven Sócrates no es necesariamente el de Platón, y tampoco la interrogación de Parménides va necesariamente más allá de la sátira. Pero lo cierto es que Platón vacila. Anota el argumento, pero no avanza allí donde Parménides lo conduce, y a donde debe conducir un idealismo auténticamente absoluto: los pelos, el barro y la basura también deben ser la Idea para que la Idea se realice sin impotencia. Todas las voces deben cantar la gloria de Dios en la inmanencia absoluta. Si no "hay" Idea de pelo, barro y basura (o, mejor, si el pelo, el barro y la basura no son también realización de la Idea, si no cantan también su gloria), las Ideas pasan a 
trascender al pelo, barro y basura. Y así lo más vil (o supuestamente más vil) de la naturaleza refutaría las más altas aspiraciones del idealismo. La separación entre mundo verdadero y sensible se traza entre la Idea y aquellas cosas ridículas, "despreciables y sin importancia". Ridícula, puede ser, pero separación al fin: y así encierran a la Idea en el mundo verdadero, y dan inicio a la historia del error. Lo bello, lo justo y lo bueno, si son territorio exclusivo de la influencia de la Idea, lejos de subirle el precio, la lanzan en el devenir nihilista. Platón no llega a conocer la esencia del universo -su idealidad- porque abandona por ridículo su esfuerzo por llegar a conocer más y más lo más determinado, lo más limitado, lo más aparentemente aparente, lo que parece sustraerse a la acción de la idea.

La caracterización de Goddard de la filosofía de Fichte que tomamos para Hegel ("no se puede pensar ningún desarrollo de lo eterno por fuera del que aparece y adviene en la temporalidad ilimitada de una historia humana" [y de la existencia de la naturaleza]) sólo será efectiva si aceptamos también la recíproca: ningún advenimiento de la historia humana y la naturaleza podrá pensarse por fuera del desarrollo de la Idea. Sólo así "el moho, sólo de fango nutrido, puede alumbrar de las rosas su esplendor amigo" ${ }^{1}$. No hay idealismo absoluto sin slum naturalism donde "la idea no teme las villas miserias [slums], no tiene miedo de ninguna de las suciedades de la vida" ${ }^{32}$. Sólo así el Idealismo será efectivamente absoluto (y el slum naturalism se revelará como slum idealism).

\section{Hegel vacila, y parece dejarnos a oscuras}

Hegel también vacila. No menos que Platón, teme internarse en los barrios bajos, en los pelos, el barro, la basura, el moho y el fango. Vacila. De alguna manera, se resiste a aceptar las consecuencias últimas de su propio pensamiento: que tanto la Idea en la mente de Dios y lo aparentemente más despreciable y sin ninguna importancia de la existencia deben ser ideales. En sus Lecciones sobre Platón, Hegel argumenta en contra de que las Ideas sean quimeras. El paso inicial, como vimos, es cuestionar la Idea como ideal, como abstracción perfecta: no son figuraciones de la fantasía ni Ideas encerradas en la mente de Dios, trascendentes, incapaces de realizarse tal como son en $\mathbf{s i}^{i 3}$. Pero en el paso siguiente cambia el acento, y el problema se traslada a la atención e importancia que el hombre le da a las faltas y máculas:

Hacer de una nimiedad o una bagatela, de la que ningún hombre razonable haría caso, una cosa importante, y tiende a creer que esas faltas y esas máculas existen, aunque se pasen por alto. Sin embargo, no es magnanimidad, sino su propia corrupción la que hace que se fijen en lo que llaman máculas y faltas. El hombre que las tiene queda inmediatamente absuelto de ellas, por si mismo, en cuanto no les da importancia alguna. Sólo se convierten en vicios si son esenciales para é ${ }^{34}$.

Las máculas y las faltas (y por tanto también el pelo, el fango y el moho) deben ser pasadas por alto. La falta es darles importancia. Y en cuanto ésta se le resta, "el hombre queda inmediatamente absuelto". Se trata, entonces, de ignorar los slums, abandonar las cosas ridículas, evitar caer en una necedad sin fondo, continuar con lo importante: lo bello, lo verdadero y lo justo. "Las cosas despreciables y sin ninguna importancia" con las que Parménides corría a Platón, son efectivamente sin importancia, y se dejan de lado. La sabiduría consiste en la capacidad de dejar de lado el vicio y la corrupción, lo temporal y lo perecedero, lo meramente natural, lo humano, demasiado humano. Las nimiedades y las bagatelas deben quedar en las sombras, lejos de la luz de lar razón: 
Los hombres son siempre viciosos y corrompidos, pero eso no es la idea. Cuando se conoce la realidad de la sustancia, hay que ver a través de la superficie (...) Lo temporal, lo perecedero, existe, pero no se trata de la verdadera realidad ${ }^{35}$. teórico: "la naturaleza ha sido enunciada como la caída de la idea desde sí misma" ${ }^{36}$. El progreso, la conformación de la naturaleza como sistema escalonado, es atribuido explícitamente a la acción de la idea y no a la naturaleza misma: "la naturaleza debe ser contemplada como un sistema escalonado (...) pero no de tal manera que cada escalón sea naturalmente generado desde los otros, sino [que lo es] en la idea interior que constituye el fundamento de la naturaleza" ${ }^{37}$. El resto, aquello que se sustrae a la acción de la Idea, la contingencia y la necesidad, la riqueza infinita y la pluralidad de formas, la irracionalidad, los monstruos y las malformaciones es atribuido a la "impotencia de la naturaleza" ${ }^{38}$. La Idea es la razón que se realiza desplegándose en el mundo. Un mundo que existe extrínseco y estúpido, "al lado" de la idea, que, por tanto, lo trasciende. La realización es un paulatino iluminarse de lo en sí oscuro. Desde esta perspectiva, la idea ignoraría zonas completas de lo real, por considerarlo sin importancia, impotente y fallido. Incluso la filosofía del espíritu aparece como un progresivo enriquecimiento de las formas limitadas, imperfectas. Una constante superación, Aufhebung perpetua que conduce al punto de vista filosófico donde la inteligencia "libre en sí" parece desprenderse de toda impureza, superando incluso a la Idea platónica en favor de la entelequia aristotélica ${ }^{39}$. Las lecturas del fin de la historia se apuntalan en pasajes bien concretos de la obra de Hegel e impugnan sin piedad la posibilidad de encontrar en Hegel la "temporalidad ilimitada de una historia humana" y mucho menos un slum naturalism. La entelequia podría ser otro nombre de las quimeras y el final del recorrido de Hegel nos volvería encerrar en la mente de Dios antes de la creación. El error más largo encontraría, como muchos han pensado, en la filosofía de Hegel su hogar por excelencia.

Este devenir, de ser tal, estaría contenido in nuce en la dialéctica de lo finito de la Ciencia de la lógica. La verdad del idealismo sería la falsedad de lo finito, y el barro, el pelo, la basura, las monstruosidades y las máculas no serían más que "momentos destinados a desaparecer en lo propiamente real" ${ }^{\prime 0}$. A esto parece, y tal es la interpretación de Zuviría, apuntar el célebre inicio de la no menos célebre "nota sobre el Idealismo": "La proposición que lo finito es ideal, constituye el idealismo. El idealismo de la filosofía no consiste en nada más que eso: no reconocer lo finito como un verdadero existente" ${ }^{41}$. $Y$ no sólo el idealismo, sino también el idealismo absoluto, tendría como marca la desvalorización de todo lo finito, según una de las escasas veces que Hegel recurrió a esta expresión que la historia de la filosofía elegiría para designar su pensamiento:

La verdadera relación es que las cosas de las cuales tenemos conocimiento inmediato son meras apariencias, no sólo para nosotros sino también en sí mismas, y que la determinación adecuada de estas cosas, que son en ese sentido "finitas", consiste en que su fundamento no está en ellas sino en la Idea divina universal. Esa interpretación también debe ser llamada idealismo, pero, a diferencia del idealismo subjetivo de la filosofía crítica, es un idealismo absoluto ${ }^{42}$.

En esta desvalorización de lo finito está el germen teórico de todo lo que Hegel parece despreciar: pelos y monstruos, máculas y deformidades, contingencia y necesidad. El idealismo absoluto sería desde esta perspectiva el agujero negro en el cual todas las determinaciones se disuelven, el Apocalipsis metafísico al que nos conduce la entropía ontológica. Las cosas son en si mismas meras apariencias, no son nada, nada. Aniquilar el 
mundo verdadero y también el aparente tendría sólo el sentido de sumergirnos en la eterna quietud en la que todas las tensiones se disuelven. La Idea, como un avatar más de la termodinámica, parece en su despliegue lanzarse en loca carrera hacia el suicidio.

\section{El silogismo que abraza lo más vil y lo más noble}

Y sin embargo, mal podría este idealismo absoluto aniquilador distinguirse del schlechten Idealismus. ¿Cómo podría aspirar a destruir la realidad sin enfrentarse a ella y otorgarle una existencia independiente, fuera de la Idea, que al idealismo repugna? ¿Qué sería la Aufhebung así concebida sino un proceso de activa demolición? El que piense esto, ignora lo fundamental, "la determinabilidad que consiste en que lo uno sea en lo otro, en lo múltiple, en lo distinto, idéntico consigo mismo" ${ }^{33}$. La potencia de la Idea es ser ella misma en lo múltiple y distinto. Estar en sí en lo para sí. Ser ella misma en las monstruosidades que parecen oponérsele. En ese sentido lo finito es ideal. Lo que es mera apariencia, lo que no es ni puede ser verdadero existente, no es lo finito, ni la naturaleza, ni las formas más precarias del espíritu, sino el saber, el modo de conocimiento que hace de ellas el punto fijo de referencia para la verdad. La idea divina universal fundamenta a las cosas finitas, pero no como algo exterior, trascendente, encerrado en la mente de Dios, sino como idea interior. Un interior que no es nuestra propiedad, nuestra posesión, la verdad de nuestra individualidad aislada, sino por el contrario la universalidad que los individuos finitos envolvemos como cáscara y azar. "Lo eterno en el interior del tiempo" ${ }^{44}$. Así fundamentar no es desfondar ni mucho menos aniquilar, sino vivificar a la multiplicidad. Tal es la potencia de la Idea: sostener la cadena entera del ser, desde la basura y el barro hasta la belleza, la justicia y el bien. Todo es así ideal, desde lo finito hasta el espíritu: "Tiene que ser llamado ideal el concepto, la idea, el espíritu" ${ }^{45}$. En efecto, en la nota sobre el idealismo Hegel usa el mismo término (ideelle) para referirse a lo finito, a lo universal, el concepto, la idea y el espíritu ${ }^{46}$.

"El punto de vista del concepto es el idealismo absoluto, y la filosofía es el conocimiento conceptual" ${ }^{\prime 7}$. El idealismo absoluto, indica Hegel en otra de las escasas veces que recurre a la expresión, no es lógica del Ser, tampoco lógica de la Esencia, sino lógica del concepto. El idealismo absoluto no un pasaje inmediato entre opuestos ${ }^{48}$ (ideal-real, finito-infinito, pensamiento-naturaleza, perfección-mácula), ni la exacerbación de las tensiones en la contradicción para llevarlos a un movimiento del infinito que sólo puede ser falso en tanto retiene una dualidad (los extremos como fundamento) que sólo puede tergiversar el verdadero movimiento de lo real. Cualquier elemento tomado en forma aislada es falso: sea un elemento lógico (incluso la idea), natural o espiritual (incluso el espíritu absoluto, incluso la filosofía). No sólo las cosas finitas "son finitas precisamente porque no tienen totalmente en sí mismas la realidad de su concepto ${ }^{49}$ ", sino también todos los otros elementos tomados en forma aislada. En el esquema progresivo-lineal de la interpretación de Hegel, la filosofía es la cúspide del sistema; pero, separada de los otros momentos, no es otra cosa que Schlechten Idealismus.

Incluso la Idea, tiene que ser parte del proceso abarcativo de la realidad (y no Idea en la mente de Dios). Esta verdad no es refutada por la afirmación según la cual "si algo tiene verdad, lo tiene por medio de su idea, o sea algo tiene verdad sólo por cuanto es idea" ${ }^{50}$. Por el contrario, esto implica que incluso la idea sólo es verdadera por medio de su idea: la capacidad de abarcar en sí lo distinto, lo despreciable y sin importancia. La luz de la razón no puede vacilar, debe avanzar hacia todos los rincones de lo real, so pena de 
dejarnos a oscuras. En ese abarcar lo múltiple, la Idea es verdadera como pura actividad de determinarse a sí misma.

De allí la importancia del silogismo de silogismos con los que cierra la Enciclopedia, sobre la que no se puede insistir lo suficiente. Allí queda restringida al primer silogismo (lógica-naturaleza-espíritu) la linealidad de la concepción progresiva del desplegarse de la Idea a partir de "la representación de Dios, tal como está en su ser eterno, antes de la creación de la naturaleza y de un espíritu finito" ${ }^{51}$ (y el lugar de mero punto de paso de la naturaleza y su impotencia). También el rol eminente de lo espiritual es matizado, ya que "el punto de vista del espíritu mismo" tiene su lugar en el segundo silogismo (naturaleza-espíritu-lógica). Lo universal absoluto se halla en el tercer silogismo (espíritu-lógica-naturaleza), donde la Idea es término medio, es un desdoblarse (sichUrteilen) de la Idea en actividad subjetiva de la Idea y en el proceso de la Idea existente (seienden Idee). En todos sus avatares, es la Idea, siempre la Idea, la Idea absoluta, que permanece en sí en lo distinto y múltiple, y que así en el los pelos y el barro, la basura y las máculas, las villas miserias y la justicia, el moho y la belleza, la verdad y el Estado, el dolor y la génesis, el alma y el monstruo, la aniquilación y el lodo, la nobleza y el llanto, "eternamente actúa, produce y disfruta" ${ }^{52}$.

\section{Bibliografía}

BAKHTIN, M. (1984) Problems of Dostoevsky's Poetics. Minneaopis: University of Minesota Press.

ESPINOZA LOLAS, R. (comp.) (2012) Hegel, la trasnformación de los espacios sociales, Concón: Midas.

FERREYRA, J. (2013) "Sobre el espíritu y la letra de las críticas de Deleuze a la Ciencia de la lógica", Estudios hegelianos, № 3, pp. 103-123.

GODDARD, J.-Ch. (1999) La philosophie fichtéenne de la vie. Paris: Vrin.

HEGEL, G.W.F. (1970f) Werke in zwanzig Bänden, Moldenhauer, E. \& Michel, K. M. (Eds.). Frankfurt am Main: Suhrkamp.

HEGEL, G. W. F. (1997) Enciclopedia de las ciencias filosóficas. Trad. Valls Plana. R. Madrid: Alianza Universidad.

Hegel, G. W. F. (1968) Ciencia de la lógica (2 tomos). Trad. Mondolfo, R. Buenos Aires: Solar.

HEGEL, G. W. F. (1955) Lecciones sobre la historia de la filosofía (3 tomos). Trad. Roces. W. México: Fondo de Cultura Económica.

NIETzsche, F., (1973) Crepúsculo de los ídolos. Trad. Sánchez Pascual, A. Madrid: Alianza Editorial.

Platón (1988) Parménides. trad. Santa Cruz, M. I., Vallejo Campos, A. y Cordero, N. Madrid: Gredos.

SANDKÜHLER, H. J. (2005), Handbuch Deutscher Idealismus. Stuttgart: Metzler.

ZUVIRÍA, M. (2014) "Infinitud e idealismo, a propósito de una nota de Hegel en la Doctrina del ser de 1832", Agora, 88, 71-88. 


\section{NOTAS}

1. “Cómo el mundo verdadero terminó convirtiéndose en una fábula", en Nietzsche 1973: 51-52. Allí Nietzsche narra cómo el mundo verdadero, representado por la Idea de Platón, fue tornándose a lo largo de la historia de la filosofía en algo sublimizado, pálido, "königsberguense" (cuando se volvió inasequible "por ahora", para nosotros), luego desconocida, luego inútil, superflua, refutada.

2. Hegel 1955/II: 194.

3. También en Fichte, aunque no lo trataremos aquí, el idealismo se derrumba si hay algo que es para el yo, algo real, que no es también ideal, que no brota de la Idea. Tal es también el sentido de la afirmación: "Todo lo que es para el yo, es por el yo" (GA, I/4, 210, el subrayado es mío). Se trata de dar cuenta del "sistema de toda la experiencia" (GA, I/4, 213, el subrayado es también mío).

4. Hegel raramente usa el término "idealismo" para referirse a su propia filosofía. Recurre a él habitualmente para referirse en forma crítica a los pensamientos de los que pretende distinguirse: idealismo subjetivo, idealismo trascendental o incluso idealismo psicológico. Los autores a los que apunta principalmente son Kant y Fichte (y en menor medida a Spinoza y Leibniz). También lo utiliza, como veremos en las Lecciones de historia de la filosofía para caracterizar una de las dos corrientes del pensamiento (idealismo y realismo) que se trata de hacer converger en torno a la idea concreta. Por otra parte, la expresión "idealismo absoluto", que se utilizará en los manuales para caracterizar a su filosofía, no tiene casi apariciones en toda su obra. Las más significativas son tres, y figuran todas en los agregados a la Enciclopedia de las Ciencias Filosóficas en compendio, es decir, no provienen directamente de la pluma de Hegel sino que han sido tomadas de los apuntes de sus alumnos. Recurrimos sin embargo a la expresión "idealismo absoluto" para designar su concepción del pensamiento que abarca tanto la realidad como el pensar, y se contrapone a lo que él llama "falso idealismo",

5. Hegel 1955/II: 194.

6. Hegel 1955/II: 135.

7. Hegel 1955/II: 160.

8. Sandkühler 2005: 1.

9. Cfr. Hegel 1968/I: 192. La nota sobre la mala infinitud precede, no por casualidad, la nota sobre el idealismo, sobre la cual vovleremos.

10. Hegel 1955/II: 161.

11. Hegel 1955/III: 208. Preferimos esta presentación de la oposición que se trata de superar a la de la secuencia idealismo subjetivo - idealismo objetivo - idealismo absoluto que, al tratar de reencontrarla en el idealismo al cual, por principio, tal oposición repugna, sólo contribuye a la confusión que intento despejar. Los escritos hegelianos de Jena, lejos de afirmar que Fichte representa el idealismo subjetivo y Schelling el objetivo, se sumergen en esas complejidades, en el esfuerzo por evitar que la oposición permanezca como subyacente a su propia filosofía: que no haría así son continuar la historia del error.

12. "La dialéctica platónica tiene en el Parménides, por una parte, sólo la intención de resolver y refutar por sí misma las afirmaciones limitadas y, por otra, obtiene sin embargo en general como resultado la nada", Hegel 1955/I:, 73. Modifico la traducción, ya que Mondolfo parece interpretar Parménides como el filósofo cuando, a mi entender, Hegel se refiere al diálogo con ese título.

13. Hegel 1968/I: 66.

14. Hegel 1955/II: 161.

15. Hegel 1955/II: 161.

16. Hegel 1955/II: 161-162. 
17. Tomar el pensamiento como meramente formal y a lo sensible como la única realidad es el primer malentendido o tergiversación de la filosofía platónica para Hegel. El segundo es pensar que las Ideas son ideales de nuestra razón, que no tienen realidad o no pueden ser alcanzadas (Hegel 1955/II, 162). En suma: ni el empirismo ni Kant son capaces de comprender a Platón ni a ninguna forma auténtica del idealismo.

18. Hegel 1968/ I: 66

19. Hegel 1997: 603-604.

20. Hegel 1997: 604.

21. Goddard 1999: 11.

22. Sobre la polémica en torno a la temporalidad en la Idea de Hegel, cfr. Espinoza Lolas, 2012 (actas de un congreso donde esta discusión ocupó un lugar central, protagonizada eminentemente por Vincenzo Vitiello y Volker Rühle). Cfr. también Ferreyra, 2013.

23. Hegel 1955/II: 218.

24. Fichte acotaría que en tanto "sustanciales" sólo pueden enfrentarse, que para comprender la unidad de las series hace falta pensarlas no como un ser sino como un actuar (GA 1/4, 212).

25. Hegel 1955/II: 217,

26. Hegel 1955/III: 208, cfr supra.

27. En términos de Fichte: ciencia, pero no Doctrina de la ciencia (GA I/4, 210).

28. Hegel 1955/II: 197.

29. Hegel 1955/II: 197.

30. Platón 1988: 43.

31. Hegel 1997: 598 (pasaje del Mewlana Dschelaleddin Rumi reproducido por Hegel en las páginas finales de la Enciclopedia, que conduce ya al silogismo de silogismos).

32. Bakhtin 1984: 115.

33. "Ideales necesarios para nuestra razón, pero cuyos productos ni tienen realidad ahora, ni pueden llegar a adquirirla nunca (...) De ser así, no serían otra cosa que figuraciones de la fantasía", Hegel 1955/II: 162.

34. Hegel 1955/II: 217.

35. Hegel 1955/II: 218-219.

36. Hegel 1997: 307

37. Hegel 1997: 308.

38. Hegel 1997: 309

39. Hegel 1997: 577

40. Zubiría 2014: 81.

41. Hegel 1968/I, 197-198.

42. Hegel 1970/8: 122-123. Las menciones al "idealismo" son en total tres, siempre como agregados a la Enciclopedia (y por tanto provenientes de los apuntes de los alumnos, y no de la pluma misma de Hegel). Utilizaremos otra más abajo. La restante dice: "La acción persistente de la vida es el idealismo absoluto; se relaciona con un Otro, que sin embargo es siempre superado. Si la vida fuera realista, tendría respeto por lo exterior; pero sin embargo inhibe constantemente la realidad del otro, y lo transforma en sí mismo" Hegel 1970/9: 338.

43. Hegel 1955/II: 194.

44. Goddard 1999: 11, cfr. supra.

45. Hegel 1968/I: 198

46. Ideell no es, por tanto, como indica Zuviría, un "terminus technicus del lenguaje filosófico que se emplea como sinónimo de «irreal», de «abstracto», o de lo que, por ser simplemente finito, resultado de una negación primera o inmediata, no es sino un momento destinado a desaparecer en lo propiamente real" (Zuviría 2014, 81).

47. Hegel 1970/8: 307 
48. Las determinaciones características de la Doctrina del ser están signadas por el pasaje inmediato: todo equivale, todo "vale junto", todas las vacas son negras. El devenir desfonda al ser y la nada, porque es su pasaje inmediato (sólo la Idea los fundamenta). De allí los peligros de tomar como la verdad del pensamiento hegeliano (así como más arriba señalábamos los peligros de hacer verdad revelada de la Doctrina de la esencia y las determinaciones de la reflexión).

49. Hegel 1968/II: 474

50. Hegel 1968/II: 471.

51. Hegel 1968/ I: 66

52. Hegel 1997: 604, trad. modificada.

\section{RESÚMENES}

Hegelian absolute idealism, far from implying an annihilating negation of the finite, means the capacity of the Idea of vivifying and being in itself in everything that exists - even in the nonimportant and most despicable forms. We will construct the authentic Hegelian idealism trough his Lectures on Plato, where Hegel already rejects the schlechten Idealismus on unilateralism grounds and finds a trought that embraces both reality and thinking. Therefore, the Idea cannot be a Chimera or remain locked in the Mind of God but must be immanent to the human and the natural. We will show how Hegel wavers (with his affirmations of the ideality of finite and the impotence of nature) and the limits of Platonism (the resistance to lose himself in the nonsense without ground to which hair, mud and garbage would lead), but also the conceptual necessity of an Idea that should leave no aspect of reality in the shadows. Doing so would mean disregarding the syllogism of syllogisms and enter in a nihilistic spiral of the history of an error.

\section{ÍNDICE}

Keywords: Hegel, absolute idealism, slum naturalism, Plato, Logic of the Concept

\section{AUTOR}

\section{JULIÁN FERREYRA}

UBA 